\title{
TITLE:
}

\section{International Competition and Distributive Class Conflict in an Open Economy Kaleckian Model}

$\operatorname{AUTHOR}(S):$

Sasaki, Hiroaki; Sonoda, Ryunosuke; Fujita, Shinya

\section{CITATION:}

Sasaki, Hiroaki ... [et al]. International Competition and Distributive Class Conflict in an Open Economy Kaleckian Model. Metroeconomica 2013, 64(4): 683-715

\section{ISSUE DATE:}

2013-08-08

URL:

http://hdl.handle.net/2433/196773

\section{RIGHT:}

(C) 2013 John Wiley \& Sons Ltd. This is the peer reviewed version of the following article: Sasaki, H., Sonoda, R. and Fujita, S. (2013), International Competition and Distributive Class Conflict in an Open Economy Kaleckian Model.

Metroeconomica, 64: 683-715, which has been published in final form at http://dx.doi.org/10.1111/meca.12030; This is not the published version. Please cite only the published version.; この論文は出版社版でありません。引用の際には出 版社版をご確認ざ利用ください。 


\title{
International Competition and Distributive Class Conflict in an Open Economy Kaleckian Model ${ }^{\dagger}$
}

\author{
Hiroaki Sasaki* \\ Graduate School of Economics, Kyoto University \\ Ryunosuke Sonoda \\ Faculty of Economics, Saga University \\ Shinya Fujita \\ Graduate School of Economics, Nagoya University
}

\begin{abstract}
This paper constructs an open economy Kaleckian model in which international competition affects the bargaining process between firms and workers, and investigates the effects of such bargaining on the macroeconomy. We show that the effects of a change in the bargaining power on aggregate demand depends not only on the demand regimes but also on which agents bears more of the burden arising from the international price competition. Moreover, if the real exchange rate has a small impact on the trade balance, the economy is stable, whereas if it has a larger impact on the trade balance, the economy is unstable.
\end{abstract}

Keywords: Kaleckian model, Open economy, International price competition, Wage bargaining

JEL Classification: E12; F43; J50

\footnotetext{
${ }^{\dagger}$ We are grateful to two anonymous referees, Takeshi Nakatani, Takeshi Ikeda, Hideo Sato, Toichiro Asada, Naoki Yoshihara, Peter Skott, and participants in the 59th JSPE annual conference at Rikkyo University and the 1st Mini Lecture Series on Analytical Political Economy at Hitotsubashi University, for their suggestions and valuable comments, which have helped us improve the paper. The usual disclaimer applies.

${ }^{*}$ Corresponding author. Graduate School of Economics, Kyoto University. Yoshida-Honmachi, Sakyo-ku, Kyoto 606-8501, JAPAN. E-mail: sasaki@econ.kyoto-u.ac.jp. Phone: +81-(0)75-753-3446
} 


\section{Introduction}

Thus far, a number of Kaleckian models have been developed, and the relation between income distribution and aggregate demand has been investigated. ${ }^{1}$ From those models, we derived a familiar result that there are two types of demand regime, wage-led and profit-led, according to the parameter constellation of investment and saving functions. ${ }^{2}$ The wage-led demand regime indicates an economy in which a rise in the profit share decreases aggregate demand and the profit-led demand regime indicates an economy in which a rise in the profit share increases aggregate demand.

Most of the Kaleckian models that investigate the relation between income distribution and aggregate demand assume a closed economy and abstract from international trade. The real economy is nevertheless an open economy, and accordingly there are complications in applying analytical results based on the assumption of a closed economy to the real world. It is necessary to construct an open economy model and derive effective implications for the real economy.

Needless to say, some of the Kaleckian models take into account an open economy case. ${ }^{3} \mathrm{~A}$ pioneering work that introduces international price competition into the Kaleckian model is Blecker (1989). By adding net export into demand components, he shows that an increase in the wage share can lower international price competitiveness and has a negative impact on investment, which implies that the wage-led demand regime is hard to obtain. Another novel idea of Blecker (1989) is the assumption that firms restrain their prices in terms of international price competition, whereas traditional Kaleckian models assume that firms determine their price as they like. This modification implies that international competition strictly affects income distribution in the domestic country.

Blecker (1989) nevertheless assumes that the measure of international price competition (i.e., the ratio of domestic unit labor cost to import prices) is exogenously given and hence

\footnotetext{
${ }^{1}$ For the so-called Kaleckian model, see Rowthorn (1981) and Lavoie (1992). As for the empirical studies on the relation between income distribution and aggregate demand based on the Kaleckian framework, see Stockhammer and Onaran (2004), Barbosa-Filho and Taylor (2006), Naastepad and Storm (2007), Hein and Vogel (2008), Stockhammer, Onaran, and Ederer (2009), and Stockhammer, Hein, and Grafl (2011).

${ }^{2}$ For a theoretical explanation of the demand regime, see Blecker (2002).

3 Cordero (2002) constructs an open economy Kaleckian model that integrates the theory of conflicting-claims inflation. This model assumes, however, that price is determined in the international goods market and formalizes only workers' bargaining process. La Marca (2010), using an open economy version of the stock-flow consistent model, considers the dynamics of the rate of capacity utilization, profit share, and trade balance. Von Arnim (2011) constructs an open economy Kaleckian model and considers the effect of the wage policy on growth and distribution by using Monte Carlo simulation.
} 
does not explicitly consider the process in which international competition influences income distribution. We therefore need to endogenize income distribution to improve the open economy model.

A representative way to endogenize the process of income distribution in a Kaleckian model is to use the theory of conflicting-claims inflation developed by Rowthorn (1977). ${ }^{4}$ This theory assumes that both firms and workers have their own target values of each distributive share and then negotiate over the price and the nominal wage in response to the gap between the actual share and their own targets.

The Cassetti (2002) model is one that takes into account the open economy case using the theory of conflicting-claims inflation. He considers the situation in which inflation of domestic products due to class conflict changes the real exchange rate, and this change affects the growth rate of the economy through exports and imports. His model is important in that it simultaneously introduces international price competition and the determination of income distribution.

Cassetti's (2002) model nevertheless leaves room for further investigation. When extending a Kaleckian model with conflict-inflation to an open economy model, he uses equations that determine the wage and price dynamics in closed economy without any modifications. In other words, he assumes that in the face of international price competition in the international goods market, firms and workers never consider foreign competition, which is unrealistic. To investigate income distribution in an open economy, we must consider the effect of international price competition on the conflict between firms and workers.

A study that considers this aspect is Missaglia (2007). He assumes that the price equation of firms depends on the real exchange rate; when the terms of trade deteriorate, firms restrain their prices. Missaglia's (2007) approach is still unsatisfactory because he does not consider the effect of international price competition on the wage bargaining of workers. The same problem holds for Blecker (1998), which is an extension of Blecker (1989).

With the ongoing globalization of the real world, just as firms have to consider international competition in setting their prices, workers also have to consider international competition in formulating their wage demands. Increasing wages recklessly in open economy causes a decrease in the price competitiveness of the domestic industry and a decline in market share

${ }^{4}$ For closed economy Kaleckian models with the theory of conflicting-claims inflation, see Cassetti (2003) and Dutt (1987). 
on the international market, which in turn causes a fall in domestic labor demand and leads to a loss of employment. In addition, if international capital flow is allowed, firms facing losses due to international price competition transfer their production base to foreign countries to seek cheaper labor. Accordingly, the pressure on domestic workers will intensify. It is therefore reasonable to suppose that workers who engage in wage bargaining pay attention to the relative price of domestic and foreign products. ${ }^{5}$

When both firms and workers consider international price competition, the effect of price pressure on income distribution has two channels. Whether the wage share or the profit share increases when international competition intensifies depends on how much firms and workers share the burden arising from price restraint.

The Blecker (2011) model accordingly assumes that international price competition affects both firms and workers. In this model, the target profit share of firms depends on the real exchange rate, and moreover, the rate of change in the nominal wage that is determined by wage bargaining depends on the real exchange rate. In his approach, however, the target profit share of workers is assumed to be constant. It is because the price of imports is indexed to the nominal wage and not because the international price competition affects the target of workers that changes in the real exchange rate affect the nominal wage. As stated above, however, it is possible that under severe international competition, labor unions revise the target downward. It is therefore necessary to build a conflict model that considers this possibility.

In addition, the Blecker (2011) model separates the determination of output (capacity utilization) from the determination of income distribution and the real exchange rate. In other words, the goods market has nothing to do with the profit share and the real exchange rate that are determined in the labor market; there is a feedback from the labor market to the goods market, but not from the goods market to the labor market.

In the present paper, we therefore present a Kaleckian model in which international price competition affects both firms' decision and workers' decisions. In addition, there is bilateral feedback from the labor market to the goods market and from the goods market to the labor market. ${ }^{6}$ Using this model, we investigate the stability of the steady state equilibrium and the

\footnotetext{
${ }^{5}$ For a model that assumes the effect of international price competition on the wage bargaining of workers, see Blecker (1996). He also introduces a real world example that supports this assumption: the labor union of Xerox Corporation accepts a sharp wage cut to prevent workers from moving abroad in the face of international price competition.

${ }^{6}$ At the steady state equilibrium of our model, the rate of inflation is constant. Accordingly, the equilibrium rate of capacity utilization can be called the "Non-Accelerating Inflation Rate of Utilization." As long as we
} 
effect of international price competition on the equilibrium values. From our analysis, we obtain the following new results.

First, with regard to the stability of the equilibrium, as long as the effect of the real exchange rate on trade balance is sufficiently small, the equilibrium is likely to be stable irrespective of which demand regime is realized in the equilibrium. By contrast, if the real exchange rate effect is large, then the equilibrium is likely to be unstable, and depending on conditions, cyclical fluctuations can occur.

Second, with regard to the comparative static analysis, even if the domestic economy is characterized by a profit-led demand regime, unlike in a closed economy, a rise in the bargaining power of firms can depress the rate of capacity utilization. Moreover, even if the domestic economy is characterized by a wage-led demand regime, unlike in a closed economy, a rise in the bargaining power of workers can depress the rate of capacity utilization.

The remainder of the paper is organized as follows. Section 2 presents our model. Section 3 investigates the dynamics of the model. Section 4 conducts comparative static analysis. Section 5 is the conclusion.

\title{
2. Model
}

Consider a small open economy in which workers and capitalists coexist. Workers consume all their wages and capitalists save a fraction $s$ of their profits. Workers and capitalists consume both domestic and foreign goods. The goods market is imperfectly competitive, and hence, firms set prices according to a mark-up pricing rule. Moreover, firms have an investment function independent of savings. The capital stock and investment consist only of domestic goods.

\subsection{Dynamics of the capacity utilization}

\begin{abstract}
identify the rate of capacity utilization with the rate of employment, we can regard $1-u^{*}$ as the "Non-Accelerating Inflation Rate of Unemployment (NAIRU)," where $u^{*}$ denotes the equilibrium value of the rate of capacity utilization. The equilibrium rate of capacity utilization depends on both the bargaining power of workers and that of firms. For example, an increase in the bargaining power of workers either positively or negatively affects the NAIRU. This result is similar to the results obtained in Storm and Naastepad (2007) and Naastepad and Storm (2010), and stands in marked contrast to the mainstream NAIRU-view, which implies that deregulation of labor market and resultant reduction in the bargaining power of workers is necessary for lowering the rate of unemployment. However, strictly speaking, the rate of capacity utilization and the rate of employment are different variables, and hence, we need to build a model in which the rate of employment is an endogenous variable if we want to find the NAIRU.
\end{abstract}


Suppose that firms operate with a fixed coefficient production function. The ratio of potential output $Y^{F}$ to the capital stock $K$ is assumed to be constant. We can then write the rate of capacity utilization as $u=Y / K$, where $Y$ denotes actual output. ${ }^{7}$ From this, we have $r=\pi u$, where $r$ and $\pi$ denote the profit rate and profit share, respectively.

Following Marglin and Bhaduri (1990), we assume that the firms' investment function is increasing in both the rate of capacity utilization and profit share:

$$
\frac{I}{K}=g_{d}(u, \pi), \quad g_{d u}>0, \quad g_{d \pi}>0,
$$

where $g_{d u}$ denotes the partial derivative with respect to the rate of capacity utilization and $g_{d \pi}$ the partial derivative with respect to the profit share.

Let us specify consumption demand. Total domestic consumption demand consists of demand for domestic goods and foreign goods. First, we assume that total nominal consumption of domestic goods is a fraction $\alpha$ of total nominal consumption expenditure.

$$
p\left(C_{w}^{D}+C_{c}^{D}\right)=\alpha[w E+(1-s) r p K],
$$

where $p$ denotes the price of domestic goods, $C_{w}^{D}$ workers' real consumption of domestic goods, $C_{c}^{D}$ capitalists' real consumption of domestic goods, $w$ the nominal wage, and $E$ employment. Next, we assume that total nominal consumption of foreign goods (i.e., total nominal imports) is a fraction $1-\alpha$ of total nominal consumption expenditure.

$$
e p^{f}\left(C_{w}^{M}+C_{c}^{M}\right)=(1-\alpha)[w E+(1-s) r p K]
$$

where $e$ denotes the nominal exchange rate in terms of home currency, $p^{f}$ the price of foreign goods that is exogenously given, $C_{w}^{M}$ workers' real consumption of foreign goods, and $C_{c}^{M}$ capitalists' real consumption of foreign goods.

Following Cassetti (2002), we assume that the expenditure coefficient for domestic goods is a function of the real exchange rate $\varepsilon=e p^{f} / p$.

$$
\alpha=\alpha(\varepsilon), \quad 0<\alpha(\cdot)<1,
$$

where $p^{f}$ denotes the price of foreign goods. How the expenditure coefficient changes when the real exchange rate changes depends on the elasticity of substitution $\rho$ between domestic goods and foreign goods. If $\rho$ is less than unity, then $\alpha$ is a decreasing function of $\varepsilon$. On

\footnotetext{
${ }^{7}$ The rate of capacity utilization is defined as $Y / Y^{F}$. Since we have $Y / Y^{F}=(Y / K) /\left(K / Y^{F}\right)$, we can use $Y / K$ as the rate of capacity utilization as long as $K / Y^{F}$ is technologically fixed and constant.
} 
the other hand, if $\rho$ is more than unity, then $\alpha$ is an increasing function of $\varepsilon$.

We specify demand for exports. Nominal exports equal real exports multiplied by the price of domestic goods. We assume that real exports are increasing in both the real exchange rate and foreign real incomes $Y^{f}$.

$$
p \cdot E X=p \cdot E X\left(\varepsilon, Y^{f}\right)=p \cdot \operatorname{ex}(\varepsilon) \cdot K \cdot Y^{f}, \quad e x^{\prime}>0,
$$

where $\operatorname{ex}(\varepsilon)$ denotes real exports per capital stock. For simplicity, we assume that real exports are linear in foreign real incomes. ${ }^{8}$

The goods market clearing condition leads to

$$
\begin{aligned}
p Y & =p C+p I+p E X-e p^{f} M \\
& =\left(p C^{D}+e p^{f} C^{M}\right)+p I+p E X-e p^{f} M, \\
& =p C^{D}+p I+p E X
\end{aligned}
$$

where $C$ denotes total consumption made up of the consumption of domestic goods $C^{D}=C_{w}^{D}+C_{c}^{D}$ and that of foreign goods $C^{M}=C_{w}^{M}+C_{c}^{M}$, and $M$ denotes imports. Note that $C^{M}=M$. Dividing both sides of equation (6) by $p K$ and substituting equations (2), (3), (4), and (5) in the resultant expression, we obtain

$$
g_{d}(u, \pi)=[1-\alpha(\varepsilon)] u+\alpha(\varepsilon) \operatorname{su} \pi-\operatorname{ex}(\varepsilon) Y^{f} .
$$

Equation (7) is a condition that holds in the equilibrium of the goods market. However, the equilibrium of the goods market is not instantaneously attained. If we denote the right-hand side of equation (7) as $g_{s}$, the excess demand of the goods market is given by $g_{d}-g_{s}$. Here, for simplicity, we assume that $Y^{f}$ is constant and unity.

We assume that in the goods market, quantity adjustment prevails.

$$
\dot{u}=\phi\left(g_{d}-g_{s}\right), \quad \phi>0,
$$

where $\phi$ denotes the speed of adjustment of the goods market. Equation (8) shows that excess demand leads to a rise in the rate of capacity utilization, while excess supply leads to a decline in the rate of capacity utilization. Substituting equation (1) and the right-hand side of equation (7) in equation (8), we obtain the dynamics of the rate of capacity utilization.

\footnotetext{
8 In our specification, the income elasticity of export demand is unity. On the other hand, in balance-of-payments-constrained growth models, originally founded by Thirlwall (1979), the sizes of the income elasticities of export and import demands are important in determining the rate of economic growth. However, as discussed below, we assume that foreign incomes $Y^{f}$ is constant. Therefore, the size of the income elasticity of export demand does not affect our results.
} 


$$
\dot{u}=\phi\left\{g_{d}(u, \pi)-[1-\alpha(\varepsilon)] u-\alpha(\varepsilon) s u \pi+\operatorname{ex}(\varepsilon)\right\}
$$

\subsection{Dynamics of the profit share}

Differentiating the definition of the profit share $\pi=1-[w /(p a)]$ with respect to time, we obtain

$$
\frac{\dot{\pi}}{1-\pi}=\hat{p}-\hat{w}+\hat{a}
$$

where $\hat{x}=\dot{x} / x$ denotes the rate of change in a variable $x$ and $a$ the level of labor productivity. In this subsection, we specify each term on the right-hand side of equation (10).

We specify changes in the domestic price and the nominal wage by using Rowthorn's (1977) conflicting-claims theory of inflation. First, suppose that firms set their price to close the gap between their target profit share $\pi_{f}$ and the actual profit share. Second, suppose that the growth rate of the nominal wage that workers manage to negotiate depends on the gap between their target profit share $\pi_{w}$ and the actual profit share.

$$
\begin{gathered}
\hat{p}=\theta_{f}\left(\pi_{f}-\pi\right), \pi_{f}=\pi_{f}(\varepsilon ; \mu), \pi_{f \varepsilon}>0, \pi_{f \mu}>0,0<\pi_{f}<1, \mu>0, \theta_{f}>0, \\
\hat{w}=\theta_{w}\left(\pi-\pi_{w}\right), \pi_{w}=\pi_{w}(\varepsilon, u ; \omega), \pi_{w \varepsilon}<0, \pi_{w u}<0, \pi_{w \omega}<0,0<\pi_{w}<1, \omega>0, \theta_{w}>0
\end{gathered}
$$

where $\mu$ and $\omega$ are shift parameters, and denote the bargaining power of firms and that of workers, respectively. The parameters $\theta_{f}$ and $\theta_{w}$ are the adjustment speed of the price and that of the nominal wage, respectively.

In our model, the two target profit shares are determined endogenously.

First, we assume that the target profit share of firms is an increasing function of the real exchange rate $\left(\pi_{f \varepsilon}>0\right)$. This means that domestic firms set their price by considering international price competition with foreign firms. When the price competitiveness of domestic firms lowers, domestic firms cut their target profit share and hence their prices to defend their market share in the international goods market.

Second, we assume that the target profit share of workers is decreasing in both the real exchange rate and the rate of capacity utilization $\left(\pi_{w \varepsilon}<0\right.$ and $\left.\pi_{w u}<0\right)$. An increase in the price of the domestic goods has a negative effect on employment and workers thus set their target profit share considering the price decrease. When the real exchange rate decreases and price competitiveness worsens, workers therefore compromise to raise the target profit share. 
We can identify an increase in the rate of capacity utilization with an increase in the rate of employment. When the rate of employment increases, workers' attitude in bargaining becomes strong, leading them to seek a higher target wage share, that is, a lower target profit share. This is known as the "reserve army effect."

Third, we assume that the target profit share of firms is increasing in the bargaining power of firms $\left(\pi_{f \mu}>0\right)$ and that the target profit share of workers is decreasing in the bargaining power of workers $\left(\pi_{w \omega}<0\right)$.

The growth rate of labor productivity is determined endogenously. Here, we assume that labor productivity growth is an increasing function of the rate of capacity utilization.

$$
\hat{a}=g_{a}(u), \quad g_{a}^{\prime}>0
$$

This specification is similar to the "reserve-army creation effect" described in Sasaki (2011, 2012), where the growth rate of labor productivity is an increasing function of the rate of employment. If the rate of employment is positively related with the rate of capacity utilization, ${ }^{9}$ that is, if Okun's law holds, we can use capacity utilization in place of the employment rate (Tavani, Flaschel, and Taylor, 2011). As the rate of employment (capacity utilization) increases and the labor market tightens, the bargaining power of workers increases, which exerts an upward pressure on wages, leading capitalists to adopt labor-saving technical changes. In other words, capitalists intentionally create unemployment (Bhaduri, 2006; Dutt, 2006; Flaschel and Skott, 2006; Sasaki, 2010, 2011).

Substituting equations (11), (12), and (13) in equation (10), we obtain the dynamics of the profit share.

$$
\frac{\dot{\pi}}{1-\pi}=\theta_{f}\left[\pi_{f}(\varepsilon ; \mu)-\pi\right]-\theta_{w}\left[\pi-\pi_{w}(\varepsilon, u ; \omega)\right]+g_{a}(u)
$$

\subsection{Dynamics of the real exchange rate}

We specify the dynamics of the real exchange rate. The rate of change in the real exchange is given as

\footnotetext{
${ }^{9}$ In the short-run, it is reasonable to think that the rate of capacity utilization and the rate of employment move in the same direction. However, in the long-run, as an anonymous referee correctly points out, these two variables are different, and so, we should consider the dynamics of the two variables separately. If we separate the dynamics of the two variables, as the closed economy models of Sasaki $(2010,2013)$ show, the number of differential equations increases, and so, analysis gets more complicated. Therefore, in the present paper, we do not separate the dynamics of the rate of utilization and those of the rate of employment. Separate analysis will be left for future research.
} 


$$
\hat{\varepsilon}=\hat{e}+\hat{p}^{f}-\hat{p},
$$

where the rate of change in the price of foreign goods, $\hat{p}^{f}$ is constant and exogenously given. Following Blecker and Seguino (2002) and Blecker (2011), we introduce a crawling peg system in regard to the nominal exchange rate:

$$
\hat{e}=\lambda(\bar{\varepsilon}-\varepsilon), \quad \bar{\varepsilon}>0, \quad \lambda>0,
$$

where $\lambda$ denotes the speed of adjustment. The currency authority has a target level of the real exchange rate $\bar{\varepsilon}$ and adjusts the nominal exchange rate according to the gap between the target and the actual levels. ${ }^{10}$ We introduce this crawling peg mechanism to investigate how the exchange rate policy of monetary authority affects the steady state equilibrium. The target level of the real exchange rate affects the equilibrium value of $\varepsilon$ as well as the adjustment path of $\varepsilon$.

Substituting equations (11) and (16) in equation (15), we obtain the following equation of the dynamics of the real exchange rate:

$$
\hat{\varepsilon}=\lambda(\bar{\varepsilon}-\varepsilon)+\hat{p}^{f}-\theta_{f}\left[\pi_{f}(\varepsilon ; \mu)-\pi\right] .
$$

\section{Dynamics of the model}

From the above analysis, the dynamics of the rate of capacity utilization, profit share, and real exchange rate are given as

$$
\begin{gathered}
\dot{u}=\phi\left\{g_{d}(u, \pi)-[1-\alpha(\varepsilon)] u-\alpha(\varepsilon) s u \pi+\operatorname{ex}(\varepsilon)\right\}, \\
\dot{\pi}=(1-\pi)\left\{\theta_{f}\left[\pi_{f}(\varepsilon ; \mu)-\pi\right]-\theta_{w}\left[\pi-\pi_{w}(\varepsilon, u ; \omega)\right]+g_{a}(u)\right\}, \\
\dot{\varepsilon}=\varepsilon\left\{\lambda(\bar{\varepsilon}-\varepsilon)+\hat{p}^{f}-\theta_{f}\left[\pi_{f}(\varepsilon ; \mu)-\pi\right]\right\} .
\end{gathered}
$$

The steady state is a situation where $\dot{u}=\dot{\pi}=\dot{\varepsilon}=0$. We let the steady state values be denoted as $u^{*}, \pi^{*}$, and $\varepsilon^{*}$. In the following analysis, we assume that there exist steady state values such that $0<u^{*}<1,0<\pi^{*}<1$, and $\varepsilon^{*}>0$. As the numerical simulations in Appendix B show, such a steady state actually exists but this result depends on functional specifications.

\footnotetext{
${ }^{10}$ According to Blecker (2011), we assume that the central bank automatically sterilizes any reserve inflows and outflows that are necessary to manage the nominal exchange rate, and accordingly, the money supply and interest rate, both are not explicitly shown in our model, are unaffected.
} 
The elements of the Jacobian matrix $\mathbf{J}$ that corresponds to the system of the differential equations are given by

$$
\begin{gathered}
J_{11} \equiv \frac{\partial \dot{u}}{\partial u}=\phi\left\{g_{d u}-[1-\alpha(\varepsilon)]-\alpha(\varepsilon) s \pi\right\} \\
J_{12} \equiv \frac{\partial \dot{u}}{\partial \pi}=\phi\left[g_{d \pi}-\alpha(\varepsilon) s u\right], \\
J_{13} \equiv \frac{\partial \dot{u}}{\partial \varepsilon}=\phi\left\{\alpha^{\prime}(\varepsilon) u(1-s \pi)+e x^{\prime}(\varepsilon)\right\} \\
J_{21} \equiv \frac{\partial \dot{\pi}}{\partial u}=(1-\pi)\left[\theta_{w} \pi_{w u}+g_{a}^{\prime}(u)\right]=(1-\pi) \Omega, \quad \text { where } \quad \Omega \equiv \theta_{w} \pi_{w u}+g_{a}^{\prime}(u), \\
J_{22} \equiv \frac{\partial \dot{\pi}}{\partial \pi}=-\left(\theta_{f}+\theta_{w}\right)(1-\pi)<0, \\
J_{23} \equiv \frac{\partial \dot{\pi}}{\partial \varepsilon}=(1-\pi)\left[\theta_{f} \pi_{f \varepsilon}+\theta_{w} \pi_{w \varepsilon}\right] \\
J_{31} \equiv \frac{\partial \dot{\varepsilon}}{\partial u}=0, \\
J_{32} \equiv \frac{\partial \dot{\varepsilon}}{\partial \pi}=\theta_{f} \varepsilon>0, \\
J_{33} \equiv \frac{\partial \dot{\varepsilon}}{\partial \varepsilon}=-\varepsilon\left(\lambda+\theta_{f} \pi_{f \varepsilon}\right)<0 .
\end{gathered}
$$

All the elements are evaluated at the steady state values. In what follows, we explain elements whose signs are ambiguous.

To conduct the analysis further, we introduce the following assumption.

Assumption 1. The condition $g_{d u}-[1-\alpha(\varepsilon)]-\alpha(\varepsilon) s \pi<0$ holds.

This condition is an open economy version of the Keynesian stability condition in which we assume that the quantity adjustment in the goods market is stable. We then have $J_{11}<0$.

Next, we introduce the following definition.

Definition 1. We define $g_{d \pi}-\alpha(\varepsilon) s u<0$ as the domestically wage-led demand regime and $g_{d \pi}-\alpha(\varepsilon) s u>0$ as the domestically profit-led demand regime.

The element $J_{12}$ shows the direct effect of an increase in the profit share on the rate of capacity utilization. If the sign is positive, a rise in the profit share increases domestic demand 
directly, which we call as domestically profit-led demand case. ${ }^{11}$ If the sign is negative, a rise in the profit share decreases domestic demand directly, which we call as domestically wage-led demand case. Note here that the partial relationship between the profit share and the rate of capacity utilization, which is represented by $J_{12}$, differs from the overall relationship between them. In regard to the overall relation between the profit share and the rate of capacity utilization, we add the following definition.

Definition 2. We call the situation where for any of the parameter changes that affect income distribution, the profit share and the rate of capacity utilization move in the opposite direction in the steady state equilibrium as the overall wage-led demand regime. On the other hand, we call the situation where for any of the parameter changes that affect income distribution, the profit share and the rate of capacity utilization move in the same direction in the steady state equilibrium as the overall profit-led demand regime.

In section 4, we will show the cases where the domestically wage-led demand (profit-led demand) regime can be compatible with the overall profit-led demand (wage-led demand) regime.

The element $J_{13}$ shows the effect of an increase in the real exchange rate on the trade balance (normalized by capital stock) $T B=\operatorname{ex}(\varepsilon)-[1-\alpha(\varepsilon)](1-s \pi) u$. If $\rho$ is more than unity, we have $\alpha^{\prime}(\varepsilon)>0$, which leads to $J_{13}>0$. This corresponds to $\partial T B / \partial \varepsilon>0$, which means that the Marshall-Lerner condition (ML condition, hereafter) is satisfied. If $\rho$ is less than unity, we have $\alpha^{\prime}(\varepsilon)<0$, which leads to $J_{13}<0$, depending on the size of $\operatorname{ex}^{\prime}(\varepsilon)>0$. In this case, the ML condition is not satisfied.

The element $J_{21}$ shows the effect of an increase in the rate of capacity utilization on the profit share. If the reserve army effect exceeds the reserve army creation effect, we have $\Omega<0$, leading to $J_{21}<0$. This corresponds to the case where the profit share is counter-cyclical to the rate of capacity utilization. On the contrary, if the reserve army creation

\footnotetext{
${ }^{11}$ We can rewrite equation (22) as follows: $J_{12}=\phi\left[g_{d \pi}-\alpha u+\alpha(1-s) u\right]$. The first term on the right-hand side shows a positive effect of a rise in the profit share on the investment, the second term shows a negative impact of an increase in the profit share on the consumption for the domestic goods from wage income, and the third term shows a positive effect of a rise in the profit share on the consumption for the domestic goods from profit income. Thus, the term "domestically profit-led demand" denotes the case where a rise in the profit share increases domestic demand, and the term "domestically wage-led demand" denotes the case where a rise in the profit share decreases domestic demand.
} 
effect exceeds the reserve army effect, we have $\Omega>0$, leading to $J_{21}>0$. This corresponds to the case where the profit share is pro-cyclical to the rate of capacity utilization.

The element $J_{23}$ shows the effect of an increase in the real exchange rate on the profit share. If firms are more responsive than workers, that is, if the absolute value of $\pi_{f \varepsilon}$ is greater than that of $\pi_{w \varepsilon}$, then $J_{23}>0$. In contrast, if workers are more responsive than firms, that is, if the absolute value of $\pi_{w \varepsilon}$ is greater than that of $\pi_{f \varepsilon}$, then $J_{23}<0$. If firms are responsive, firms bear the burden arising from international price competition more than workers, but if workers are more responsive, workers bear the burden arising from international price competition more than firms.

By deriving the characteristic equation that corresponds to the Jacobian matrix $\mathbf{J}$ and examining the corresponding characteristic roots, we can investigate the local stability of the steady state equilibrium. ${ }^{12}$ For clarification of analysis, we use the following two assumption:

Assumption 2. Both $g_{d \pi}-\alpha(\varepsilon) s u<0$ and $\Omega>0$ hold.

Assumption 3. Both $g_{d \pi}-\alpha(\varepsilon) s u>0$ and $\Omega<0$ hold.

Assumption 2 corresponds to the case where the economy is in the domestically wage-led demand regime and the reserve army creation effect exceeds the reserve army effect. Then, we have both $J_{12}<0$ and $J_{21}>0$. Assumption 3 corresponds to the case where the economy is in the domestically profit-led demand regime and the reserve army effect exceeds the reserve army creation effect. We then have $J_{12}>0$ and $J_{21}<0$.

Using these assumptions, we obtain the following proposition:

Proposition 1. Suppose that the effect of the real exchange rate on the trade balance is small, that is, the absolute value of $\partial T B / \partial \varepsilon$ is small. Then, irrespective of whether or not the ML condition is satisfied, the combination of either the domestically wage-led demand regime and $\Omega>0$ or the domestically profit-led demand regime and $\Omega<0$ makes the steady state equilibrium stable.

Proof. See Appendix A.1.

${ }^{12}$ For details of the stability analysis, see Appendix A. 
As Appendix C shows, in a closed economy, the combination of the domestically wage-led demand regime and $\Omega>0$ (i.e., the reserve army creation effect exceeds the reserve army effect), or the domestically profit-led demand regime and $\Omega<0$ (the reserve army effect exceeds the reserve army creation effect) is a stability condition. In the open economy, if the effect of the real exchange rate on the trade balance is small, these combinations are also the stability conditions.

We also obtain the two further propositions:

Proposition 2. Suppose that the effect of the real exchange rate on the trade balance is large, that is, the absolute value of $\partial T B / \partial \varepsilon$ is large. Then, if the ML condition is satisfied, the combination of the domestically wage-led demand regime and $\Omega>0$ makes the steady state equilibrium unstable. On the other hand, if the ML condition is not satisfied, under the combination of the domestically wage-led demand regime and $\Omega>0$, limit cycles occur when the speed of adjustment of the goods market lies within some range.

\section{Proof. See Appendix A.2.}

Proposition 3. Suppose that the effect of the real exchange rate on the trade balance is large, that is, the absolute value of $\partial T B / \partial \varepsilon$ is large. Then, if the ML condition is satisfied, under the combination of the domestically profit-led demand regime and $\Omega<0$, limit cycles occur when the speed of adjustment of the goods market lies within some range. On the other hand, if the ML condition is not satisfied, the combination of the domestically profit-led demand regime and $\Omega<0$ makes the steady state equilibrium unstable.

\section{Proof. See Appendix A.3.}

We now explain why there occur limit cycles when the speed of adjustment of the goods market is medium. First, when $\phi$ is sufficiently close to zero, the rate of capacity utilization is not adjusted and the analysis of the dynamic system therefore amounts to the analysis of the subsystem that consists of the profit share and the real exchange rate. After some calculations, we find that the dynamics of the subsystem are stable. Second, when $\phi$ is sufficiently large, 
the rate of capacity utilization is adjusted immediately and the effect of the rate of capacity utilization on the dynamical system therefore does not last. In this case, too, the analysis of the dynamic system amounts to the analysis of the subsystem that consists of the profit share and the real exchange rate. When $\phi$ takes an intermediate value, the rate of capacity utilization changes with lags. The rate of capacity utilization therefore has a lasting effect on the dynamical system and, accordingly, cyclical fluctuations occur.

Propositions 1, 2, and 3 are summarized in Figure 1.

[Figure 1 around here]

\section{Comparative static analysis}

This section examines the effect of changes in the saving rate of capitalists, the bargaining powers of firms and workers, and the target value of the real exchange rate on the steady state values of the rate of capital utilization, profit share, and the real exchange rate. ${ }^{13}$ Here, we only consider the stable steady state: Assumption 1 holds, either Assumption $2\left(J_{12}<0\right.$ and $\left.J_{21}>0\right)$ or Assumption $3\left(J_{12}>0\right.$ and $\left.J_{21}<0\right)$ holds, the trade balance does not respond much to the real exchange rate (i.e., the absolute value of $\partial T B / \partial \varepsilon$ is sufficiently small), and $\operatorname{det} \mathbf{J}<0$ holds. In addition, we suppose here that the ML condition is always satisfied, that is, $J_{13}>0$ holds. $^{14}$

\subsection{Saving rate of capitalists}

We represent the effect of a change in the saving rate of capitalists on the rate of capacity utilization as follows:

$$
\frac{d u^{*}}{d s}=\frac{\alpha \varepsilon(1-\pi) \pi u\left[\lambda+\theta_{f} \theta_{w}\left(\pi_{f \varepsilon}-\pi_{w \varepsilon}\right)\right]}{\operatorname{det} \mathbf{J}}<0 .
$$

Equation (30) thus means that the paradox of thrift holds even in an open economy version of the Kaleckian model: an increase in the saving rate of capitalists reduces the rate of capacity utilization.

\footnotetext{
${ }^{13}$ The current analysis abstracts from the effect of the price of foreign goods on the steady state values. This is because, for the home country, a rise in the target value of the real exchange rate is equivalent to a rise in the price of foreign goods in the sense that they both produce the same results.

${ }^{14}$ The results of the comparative static analysis in the case where the ML condition does not hold is more complicated than those in the case where the condition holds. We therefore do not investigate the former case.
} 
The effects of a change in the saving rate of capitalists on the profit share and the real exchange rate are given by

$$
\begin{aligned}
\frac{d \pi^{*}}{d s} & =\frac{-\alpha \pi u J_{21} J_{33}}{\operatorname{det} \mathbf{J}} . \\
\frac{d \varepsilon^{*}}{d s} & =\frac{\alpha \pi u J_{21} J_{32}}{\operatorname{det} \mathbf{J}} .
\end{aligned}
$$

As described above, an increase in the saving rate of capitalists decreases the rate of capacity utilization. When the reserve army creation effect exceeds the reserve army effect $\left(J_{21}>0\right)$, a decline in the rate of capacity utilization reduces labor productivity growth and thus the profit share $\left(d \pi^{*} / d s<0\right)$. Furthermore, a fall in the profit share decreases the real exchange rate $\left(d \varepsilon^{*} / d s<0\right)$ because a loss of profitability urges capitalists to raise the price of domestic goods.

On the other hand, if the reserve army effect is stronger than the reserve army creation effect $\left(J_{21}<0\right)$, a rise in the saving rate of capitalists leads to a rise in the profit share $\left(d \pi^{*} / d s>0\right)$. This is because a fall in the rate of capacity utilization decelerates nominal wage growth. An increase in profitability, moreover, leaves room for lowering the price of domestic goods. Consequently, an increase in the saving rate of capitalists raises the real exchange rate $\left(d \varepsilon^{*} / d s>0\right)$.

\subsection{Bargaining powers of firms and workers}

The next task is to investigate the effects of the bargaining power of firms and workers on the steady state values of the key endogenous variables. Because it is difficult to derive purely analytical results from our model, we here confine ourselves to pointing out that the propositions obtained in a closed version of a Kaleckian model may not be applied to an open economy case.

We represent an effect of an increase in the firms' bargaining power on the rate of capacity utilization as follows:

$$
\frac{d u^{*}}{d \mu}=\frac{-\theta_{f} \pi_{f \mu} J_{13} J_{32}+\theta_{f} \pi_{f \mu} J_{12} J_{33}-\theta_{f} \pi_{f \mu} J_{13} J_{22}+\theta_{f} \pi_{f \mu} J_{12} J_{23}}{\operatorname{det} \mathbf{J}} .
$$

As Appendix $\mathrm{C}$ shows, in a closed economy, a rise in the bargaining power of firms has a strictly positive impact on the rate of capacity utilization under a domestically profit-led demand regime. In an open economy, however, this may not occur.

Assume that the rate of capacity utilization is domestically profit-led $\left(J_{12}>0\right)$. The first 
and second terms on the right-hand side of equation (33) are thus positive, whereas the third and fourth terms are negative if $J_{23}>0$. If the latter effects are larger than the former effects, a rise in the bargaining power of firms reduces the rate of capacity utilization even under the domestically profit-led demand regime. The story behind such a situation is explained as follows. An increase in the firms' bargaining power puts upward pressure on the price of domestic goods, which in turn leads to a decline in the real exchange rate. A direct effect of a decrease in the real exchange rate is that it worsens the trade balance and the rate of capacity utilization (the third term); its indirect effect is that it reduces the profit share and thus shrinks domestic demand under the domestically profit-led demand regime if firms bear the burden arising from international price competition more than workers (the fourth term).

The effect of an increase in the workers' bargaining power on the rate of capacity utilization is given as

$$
\frac{d u^{*}}{d \omega}=\frac{-\theta_{w} \pi_{w \omega} J_{13} J_{32}+\theta_{w} \pi_{w \omega} J_{12} J_{33}}{\operatorname{det} \mathbf{J}}
$$

A well-known implication of equation (34) is that it is hard to allow workers to strengthen their bargaining power in an open economy. ${ }^{15}$ The first (negative) term on the right-hand side of equation (34) implies that an increase in the workers' bargaining power reduces firms' profitability and forces firms to push up the price of domestic goods; a rise in the price of domestic goods, in turn, decreases the rate of capacity utilization by deteriorating terms of trade. This gives a reason to justify weakening the bargaining power of workers that confront international price competition, irrespective of which demand regime is realized.

Next, we represent the impact of a change in the firms' bargaining power on the profit share as follows:

$$
\frac{d \pi^{*}}{d \mu}=\frac{-\theta_{f} \pi_{f \mu} J_{11} J_{33}+\theta_{f} \pi_{f \mu} J_{13} J_{21}-\theta_{f} \pi_{f \mu} J_{11} J_{23}}{\operatorname{det} \mathbf{J}} .
$$

It is likely that an increase in the bargaining power of firms raises the profit share, but the result is not so simple in an open economy framework. For instance, if $\theta_{w}$ is sufficiently small, we have $J_{21}>0$ and $J_{23}>0$, both the second and third terms on the right-hand side of equation (35) show a negative sign, which implies that there exists a possibility of increasing bargaining power of firms reducing the profit share. Strengthening its bargaining

\footnotetext{
15 This point is stressed by Blecker (2011) and Cassetti (2012). They show that cutting down a mark-up rate of domestic goods as well as decreasing nominal wage causes higher growth under the domestically wage-led demand case in an open economy.
} 
power raises the price of domestic goods and decreases the real exchange rate. A decline in the real exchange rate, in turn, leads to decreases in the rate of capacity utilization. If the adjustment speed of the nominal wage is sufficiently slow, then the reserve army creation effect becomes larger than the reserve army effect, and the profit share decreases (the second term). Also, if the adjustment speed of the nominal wage is sufficiently slow, then firms bear the burden arising from international price competition more than workers, and the profit share decreases (the third term).

In contrast, the effect of a change in the workers' bargaining power on the profit share is very simple.

$$
\frac{d \pi^{*}}{d \omega}=\frac{-\theta_{w} \pi_{w \omega} J_{11} J_{33}}{\operatorname{det} \mathbf{J}}<0
$$

Irrespective of the sign of $J_{23}$, the right-hand side of equation (36) is necessarily negative. In other words, irrespective of whether or not firms are more responsive than workers, strengthening workers' bargaining power decreases the profit share. This is because an increase in workers' bargaining power $\omega$ decreases their target profit share $\pi_{w}$, which has a negative impact on the profit share.

We represent the effect of a change in the firms' bargaining power on the real exchange rate as follows:

$$
\frac{d \varepsilon^{*}}{d \mu}=\frac{\theta_{f} \pi_{f \mu}\left(J_{11} J_{22}-J_{12} J_{21}\right)+\theta_{f} \pi_{f \mu} J_{11} J_{32}}{\operatorname{det} \mathbf{J}} .
$$

Under either Assumption 2 or Assumption 3, the sign of the first term on the right-hand side of equation (37) is negative, whereas the sign of the second term is positive. The result is therefore ambiguous.

The effect of a change in the workers' bargaining power on the real exchange rate is given as

$$
\frac{d \varepsilon^{*}}{d \omega}=\frac{\theta_{w} \pi_{w \omega} J_{11} J_{32}}{\operatorname{det} \mathbf{J}}<0
$$

Equation (38) shows that an increase in the workers' bargaining power reduces firms' profitability and firms push up the price of domestic goods, which in turn decreases the real exchange rate.

\subsection{Target value of the real exchange rate}

Governments often seek to raise the real exchange rate (devalue the currency) with the 
intention of improving the trade balance and stimulating output and employment. To begin with, we consider the effect of an increase in the target value of the exchange rate on its own steady state value:

$$
\frac{d \varepsilon^{*}}{d \bar{\varepsilon}}=\frac{-\lambda\left(J_{11} J_{22}-J_{12} J_{21}\right)}{\operatorname{det} \mathbf{J}}>0
$$

Because $d \varepsilon^{*} / d \bar{\varepsilon}>0$ is obtained from $J_{11} J_{22}-J_{12} J_{21}>0$, raising the target value of the real exchange rate increases its steady-state value. As mentioned above, if the ML condition is satisfied, we have $J_{13}>0$, and hence, $\partial T B / \partial \varepsilon>0$. Therefore, when governments devalue their home currencies, the trade balance is necessarily improved because of a rise in the real exchange rate.

However, even if the trade balance is improved, the rate of capacity utilization does not necessarily increase. Next, we investigate whether the attempt to depreciate the exchange rate (i.e., raising the target value of the real exchange rate) succeeds in stimulating output.

$$
\frac{d u^{*}}{d \bar{\varepsilon}}=\frac{\lambda J_{13} J_{22}-\lambda J_{12} J_{23}}{\operatorname{det} \mathbf{J}}
$$

The sign of the first term on the right-hand side of equation (40) is positive, which implies that a rise in the real exchange rate improves the trade balance, whereas the sign of the second term is ambiguous. The depreciation policy therefore may not work. The story behind the failure of that policy is explained as follows.

Suppose that the economy exhibits a domestically profit-led demand regime $\left(J_{12}>0\right)$ and workers are more responsive to the change of the real exchange rate than firms $\left(J_{23}<0\right)$. Under these assumptions, the sign of the second term on the right-hand side of equation (40) is negative. A rise in the real exchange rate caused by the depreciation policy stimulates foreign demand as long as the ML condition is satisfied (the first term). At the same time, the depreciation policy triggers workers to demand a higher nominal wage, which causes a decline in the profit share and stagnation of domestic demand. The total effect is therefore ambiguous. To succeed in the depreciation policy under the domestically profit-led demand regime, it is necessary for firms to bear the burden arising from international price competition.

Next, we assume that the domestically wage-led demand regime is realized $\left(J_{12}<0\right)$ and firms are more responsive to the change of the real exchange rate than workers $\left(J_{23}>0\right)$. In this case, the currency depreciation may not work because the sign of second term is negative. A rise in the real exchange rate increases the profit share by increasing the price of domestic goods, which in turn causes a decline in domestic demand. Under a domestically wage-led 
demand regime, the nominal wage must therefore rise higher than the price of domestic goods to stimulate aggregate demand by means of the depreciation policy.

Finally, we represent the effect of a change in the real exchange rate on the profit share as follows:

$$
\frac{d \pi^{*}}{d \bar{\varepsilon}}=\frac{-\lambda J_{13} J_{21}+\lambda J_{11} J_{23}}{\operatorname{det} \mathbf{J}} .
$$

If the reserve army creation effect is stronger than the reserve army effect, the depreciation policy raises the rate of capacity utilization by improving the trade balance, and increases the profit share (i.e., the sign of the first term on the right-hand sided of equation (41) is positive). On the other hand, if the reserve army effect is stronger than the reserve army creation effect, the policy decreases the profit share (i.e., the sign of the first term is negative).

In addition, when firms are more responsive to the change of the real exchange rate than workers, the depreciation policy raises the price of domestic goods and increases the profit share (i.e., the sign of the second term is positive). When workers are more responsive, however, this policy reduces the profit share through higher nominal wage growth (i.e., the sign of the second term is positive).

\subsection{Summary}

Table 1 shows the results of comparative static analysis in the case where the domestically wage-led demand regime is realized and the reserve army creation effect is larger than the reserve army effect, while Table 2 shows the results of the case in which the domestically profit-led demand regime is realized and the reserve army effect is larger than the reserve army creation effect.

Let us review the key points obtained from our analysis.

First, the paradox of thrift holds even in the open economy Kaleckian model.

Second, to succeed in a depreciation policy for stimulating aggregate demand, it is necessary for the government to consider both the demand regime in the domestic economy and who bears more of the burden of international price competition, workers or firms.

Third, the domestic relation between the profit share and the rate of capacity utilization differs from the overall relation between them. For instance, as Table 2 shows, a rise in the bargaining power of firms may increase the profit share and decrease the rate of capacity utilization under the domestically profit-led demand regime, which implies that a domestically 
profit-led demand regime can be compatible with an overall wage-led demand regime. Thus, the domestic demand regime is not sufficient to tell us whose bargaining power should be raised to increase aggregate demand. Moreover, the overall regime is merely a consequence of comparative static analysis with regard to the parameter changes that affect income distribution. Therefore, we should concentrate on the effects of the bargaining powers of firms and workers on the rate of capacity utilization rather than the domestic and /or overall demand regime. In what follows, we compare our results with regard to the bargaining power with those of Blecker (2011) and Cassetti (2012). ${ }^{16}$

In Blecker (2011), a decrease in the target profit share of workers decreases the steady state value of the profit share but has an ambiguous effect on the steady state value of the rate of capacity utilization under the domestically wage-led demand regime. Furthermore, under this regime, a decrease in the degree of the market share of the firm (i.e., a decline in the price of domestic goods) decreases the profit share but increases the rate of capacity utilization in the steady state equilibrium. Thus, Blecker (2011) obtains $d u^{*} / d \pi_{w}>0$ or $<0$ and $d u^{*} / d \pi_{f}<0$.

Cassetti (2012) also assumes a domestically wage-led growth regime. In this situation, a domestically wage-led demand regime holds if the Keynesian stability condition is satisfied. A decrease in the target value of the profit share of workers decreases the steady state value of the rate of capital accumulation, and an increase in the target profit share of firms has negative impact on the steady-state value of the rate of capital accumulation (i.e., $d g^{*} / d \pi_{w}>0$ and $\left.d g^{*} / d \pi_{f}<0\right)$.

In our model, a decrease in the bargaining power of workers is represented by an increase in $\pi_{w}$ while an increase in the bargaining power of firms is represented by a rise in $\pi_{f}$. If we assume the domestically wage-led demand regime, we have $d u^{*} / d \pi_{w}>0$ or $<0$ and $d u^{*} / d \pi_{f}>0$ or $<0$. This is because the effect of a change in the bargaining power on the rate of capacity utilization depends on which domestic demand regime is realized and which agents, firms or workers, bear more of the burden arising from international price competition. Depending on the combination of these two factors, there exist various scenarios that might unfold under international competition.

\footnotetext{
${ }^{16}$ In the following discussion, we change the notations of Blecker (2011) and Cassetti (2012) into ours. Cassetti (2012) considers raw material imports, whereas we do not because our aim is to investigate the effect of international competition on the wage bargaining (especially on the target profit shares of workers and firms) and not to investigate the effect internationalization through raw material imports.
} 
[Tables 1 and 2 around here]

\section{Conclusions}

This paper has presented an open economy Kaleckian model, considering the process in which international price competition affects wage bargaining between firms and workers and the effect of such bargaining on the stability of the equilibrium and the steady-state values of the endogenous variables. In particular, the analysis shows that some of the propositions obtained from a closed economy Kaleckian model do not hold in an open economy model, and even some previous results from open economy Kaleckian models are overturned or shown to be special cases. Our results can be summarized as follows.

Stability analysis. (1) The stability conditions in the closed economy case (i.e., the combination of either the domestically wage-led demand regime and a larger reserve army creation effect or the domestically profit-led demand regime and a larger reserve army effect) are accepted in the open economy case where a change in the real exchange rate has a small impact on the trade balance. (2) By contrast, if a change in the real exchange rate has a larger impact on the trade balance, the steady state becomes unstable. (3) Moreover, if the ML condition is satisfied under the combination of the domestically profit-led demand regime and a larger reserve army effect, limit cycles occur as long as the speed of adjustment of the goods market lies within some range.

Comparative static analysis. (4) The paradox of thrift is true even in the open economy setting. (5) Strengthening the firms' bargaining power may depress an economy that exhibits a domestically profit-led demand regime, but may not reduce the rate of capacity utilization under a domestically wage-led demand regime. We therefore conclude that not only the domestic demand regimes but also which agents, firms or workers, bear the burden arising from international price competition determines the effect of the bargaining power on the aggregate demand. (6) Furthermore, the success of a depreciation policy for stimulating output and employment depends on how to spread the burden of international price competition between firms and workers as well as the demand regime. 


\section{Appendix A: Stability analysis and proofs of propositions}

The characteristic equation that corresponds to the Jacobian matrix $\mathbf{J}$ is given as

$$
q^{3}+a_{1} q^{2}+a_{2} q+a_{3}=0
$$

where $q$ denotes a characteristic root. The coefficients of equation (A1) are given by

$$
\begin{gathered}
a_{1}=-\operatorname{tr} \mathbf{J}=-\left(J_{11}+J_{22}+J_{33}\right)>0, \\
a_{2}=\left(J_{22} J_{33}-J_{23} J_{32}\right)+\left(J_{11} J_{33}\right)+\left(J_{11} J_{22}-J_{12} J_{21}\right), \\
a_{3}=-\operatorname{det} \mathbf{J}=-J_{11}\left(J_{22} J_{33}-J_{23} J_{32}\right)+J_{21}\left(J_{12} J_{33}-J_{13} J_{32}\right),
\end{gathered}
$$

where $\operatorname{tr} \mathbf{J}$ denotes the trace of $\mathbf{J}$ and $\operatorname{det} \mathbf{J}$ the determinant of $\mathbf{J}$.

The necessary and sufficient conditions for the local stability of the steady state equilibrium are given by $a_{1}>0, a_{2}>0, a_{3}>0$, and $a_{1} a_{2}-a_{3}>0$. We investigate whether or not these conditions are satisfied. In our model, the coefficients of the characteristic equation are linear functions of $\phi$, the speed of adjustment of $u$, and hence, $a_{1} a_{2}-a_{3}$ is a quadratic function of $\phi$, where $^{17}$

$$
\begin{gathered}
a_{1}=\Delta_{1} \phi+\Delta_{2}, \\
a_{2}=\Delta_{3} \phi+\Delta_{4}, \\
a_{3}=\Delta_{5} \phi, \\
a_{1} a_{2}-a_{3}=f(\phi) \equiv\left(\Delta_{1} \Delta_{3}\right) \phi^{2}+\left(\Delta_{1} \Delta_{4}+\Delta_{2} \Delta_{3}-\Delta_{5}\right) \phi+\Delta_{2} \Delta_{4} .
\end{gathered}
$$

In the following analysis, we explain the coefficients $\Delta_{1}, \Delta_{2}, \Delta_{3}, \Delta_{4}$, and $\Delta_{5}$.

To begin with, the signs of $\Delta_{1}, \Delta_{2}$, and $\Delta_{4}$ are immediately obtained as

$$
\begin{gathered}
\Delta_{1}=[1-\alpha(\varepsilon)]+\alpha(\varepsilon) s \pi-g_{d u}>0, \\
\Delta_{2}=\left(\theta_{f}+\theta_{w}\right)(1-\pi)+\varepsilon\left(\lambda+\theta_{f} \pi_{f \varepsilon}\right)>0, \\
\Delta_{4}=\varepsilon(1-\pi)\left[\left(\theta_{f}+\theta_{w}\right) \lambda+\theta_{f} \theta_{w}\left(\pi_{f \varepsilon}-\pi_{w \varepsilon}\right)\right]>0 .
\end{gathered}
$$

$\Delta_{1}>0$ is obtained from Assumption 1, and $\Delta_{4}>0$ is obtained from both $\pi_{f \varepsilon}>0$ and

${ }^{17}$ We use the fact that the speed of adjustment of the goods market $\phi$ affects the dynamic process of the model but not the steady state values. 
$\pi_{w \varepsilon}<0$.

Next, the coefficient $\Delta_{3}$ can be expressed as

$$
\Delta_{3}=\left\{[1-\alpha(\varepsilon)]+\alpha(\varepsilon) s \pi-g_{d u}\right\}\left[\left(\theta_{f}+\theta_{w}\right)(1-\pi)+\varepsilon\left(\lambda+\theta_{f} \pi_{f \varepsilon}\right)\right]-(1-\pi)\left[g_{d \pi}-\alpha(\varepsilon) s u\right] \Omega .
$$

From this, if Assumption 2 holds, that is, $g_{d \pi}-\alpha(\varepsilon) s u<0$ and $\Omega>0$ hold, we have $\Delta_{3}>0$, and if Assumption 3 holds, that is, $g_{d \pi}-\alpha(\varepsilon) s u>0$ and $\Omega<0$ hold, we also have $\Delta_{3}>0$.

The coefficient $\Delta_{5}$ can be expressed as

$$
\begin{aligned}
\Delta_{5} & =\varepsilon(1-\pi)\left\{\left[1-g_{d u}-\alpha(\varepsilon)(1-s \pi)\right]\left[\left(\theta_{f}+\theta_{w}\right) \lambda+\theta_{f} \theta_{w}\left(\pi_{f \varepsilon}-\pi_{w \varepsilon}\right)\right]\right. \\
& \left.-\Omega\left\{\left[g_{d \pi}-\alpha(\varepsilon) s u\right]\left(\lambda+\theta_{f} \pi_{f \varepsilon}\right)+\theta_{f}\left[\alpha^{\prime}(\varepsilon) u(1-s \pi)+e x^{\prime}(\varepsilon)\right]\right\}\right\}
\end{aligned}
$$

The first line of the right-hand side of equation (A13) is always positive. Let us focus on the second line.

First, when Assumption 2 holds and the ML condition is satisfied, the sign of the second line depends on the absolute size of the following term:

$$
-\theta_{f} \Omega\left[\alpha^{\prime}(\varepsilon) u(1-s \pi)+e x^{\prime}(\varepsilon)\right]
$$

If expression (A14) is small, we have $\Delta_{5}>0$, leading to $a_{3}>0$. This effect is small when $\alpha^{\prime}(\varepsilon)>0$ is small and $e x^{\prime}(\varepsilon)>0$ is small, that is, when the expenditure coefficient for domestic goods is not so responsive to the real exchange rate and when export demand is not so responsive to the real exchange rate. In other words, when the trade balance is not so responsive to the real exchange rate, then $\partial T B / \partial \varepsilon>0$ is small. By contrast, if Assumption 2 holds and the ML condition is not satisfied, $\Delta_{5}>0$ necessarily holds.

Second, when Assumption 3 holds and the ML condition is satisfied, $\Delta_{5}>0$ necessarily holds. By contrast, when Assumption 3 holds and the ML condition is not satisfied, we have $\Delta_{5}>0$ as long as the absolute value of $\partial T B / \partial \varepsilon<0$ is small, which is to say, close to zero.

Finally, we investigate the sign of $\Delta_{1} \Delta_{4}+\Delta_{2} \Delta_{3}-\Delta_{5}$. If the sign is positive, we always have $a_{1} a_{2}-a_{3}>0$. On the other hand, if the sign is negative and its absolute value is large, we have $a_{1} a_{2}-a_{3}<0$.

$$
\begin{aligned}
& \Delta_{1} \Delta_{4}+\Delta_{2} \Delta_{3}-\Delta_{5} \\
= & {\left[\left(\theta_{f}+\theta_{w}\right)(1-\pi)+\varepsilon\left(\lambda+\theta_{f} \pi_{f \varepsilon}\right)\right]^{2}\left(1-\alpha+\alpha s \pi-g_{d u}\right) } \\
& -(1-\pi) \Omega\left\{\left(\theta_{f}+\theta_{w}\right)(1-\pi)\left(g_{d \pi}-\alpha s u\right)-\theta_{f} \varepsilon\left[\alpha^{\prime}(\varepsilon) u(1-s \pi)+e x^{\prime}(\varepsilon)\right]\right\}
\end{aligned} .
$$

The first line of the right-hand side of equation (A15) is always positive. Let us focus on the 
second line.

When Assumption 2 holds and the ML condition is satisfied, the second line of equation (A15) is always positive and hence, we have $\Delta_{1} \Delta_{4}+\Delta_{2} \Delta_{3}-\Delta_{5}>0$, leading to $a_{1} a_{2}-a_{3}>0$. By contrast, when Assumption 2 holds and the ML condition is not satisfied, we have $\Delta_{1} \Delta_{4}+\Delta_{2} \Delta_{3}-\Delta_{5}>0$ as long as the absolute value of $\partial T B / \partial \varepsilon<0$ is small, which is to say, close to zero.

When Assumption 3 holds and the ML condition is satisfied, we have $\Delta_{1} \Delta_{4}+\Delta_{2} \Delta_{3}-\Delta_{5}>0$ if $\partial T B / \partial \varepsilon>0$ is small because the second line is positive. By contrast, when Assumption 3 holds and the ML condition is not satisfied, $\Delta_{1} \Delta_{4}+\Delta_{2} \Delta_{3}-\Delta_{5}>0$ necessarily holds.

\section{A.1 Proof of proposition 1}

Irrespective of the sign of $\partial T B / \partial \varepsilon$, if the absolute value of $\partial T B / \partial \varepsilon$ is small, we have $\Delta_{5}>0$ and $\Delta_{1} \Delta_{4}+\Delta_{2} \Delta_{3}-\Delta_{5}>0$. From this, we have $a_{1}>0, a_{2}>0, a_{3}>0$, and $a_{1} a_{2}-a_{3}>0$. All the necessary and sufficient conditions are therefore satisfied.

\section{A.2 Proof of proposition 2}

First part: If $\partial T B / \partial \varepsilon>0$ is large, we have $\Delta_{5}<0$ and $\Delta_{1} \Delta_{4}+\Delta_{2} \Delta_{3}-\Delta_{5}>0$. Then, we have $a_{1}>0, a_{2}>0, a_{3}<0$, and $a_{1} a_{2}-a_{3}>0$, which means that one condition is not satisfied. The steady state equilibrium is therefore unstable.

Second part: If the absolute value of $\partial T B / \partial \varepsilon<0$ is large, we have $\Delta_{5}>0$ and $\Delta_{1} \Delta_{4}+\Delta_{2} \Delta_{3}-\Delta_{5}<0$. If the absolute value of $\Delta_{1} \Delta_{4}+\Delta_{2} \Delta_{3}-\Delta_{5}<0$ is large, it is possible that the sign of $f(\phi)=\left(\Delta_{1} \Delta_{3}\right) \phi^{2}+\left(\Delta_{1} \Delta_{4}+\Delta_{2} \Delta_{3}-\Delta_{5}\right) \phi+\Delta_{2} \Delta_{4}$ alternates. The quadratic function $f(\phi)$ is convex downwards and its intercept is positive. If the discriminant of $f(\phi)=0$ is positive, the equation $f(\phi)=0$ has two positive real roots: for $\phi \in\left(0, \phi_{1}\right)$, we have $a_{1}>0, a_{2}>0, a_{3}>0$, and $a_{1} a_{2}-a_{3}>0$; for $\phi \in\left(\phi_{1}, \phi_{2}\right)$, we have $a_{1}>0, a_{2}>0$, $a_{3}>0$, and $a_{1} a_{2}-a_{3}<0$; and for $\phi>\phi_{2}$, we have $a_{1}>0, a_{2}>0, a_{3}>0$, and $a_{1} a_{2}-a_{3}>0$. There thus occurs the Hopf bifurcation at $\phi=\phi_{1}$ and $\phi=\phi_{2}$. Indeed, at $\phi=\phi_{1}$ and $\phi=\phi_{2}$, we have $a_{1}>0, a_{2}>0, a_{3}>0, a_{1} a_{2}-a_{3}=0$, and $\partial\left(a_{1} a_{2}-a_{3}\right) /\left.\partial \phi\right|_{\phi=\phi_{1} \text { or } \phi_{2}} \neq 0$, which mean that all the conditions for the Hopf bifurcation are satisfied. There therefore exists a continuous family of non-constant, periodic solutions of the system around $\phi=\phi_{1}$ and $\phi=\phi_{2}$. 


\section{A.3 Proof of proposition 3}

First part: If $\partial T B / \partial \varepsilon>0$ is large, we have $\Delta_{4}>0$ and $\Delta_{1} \Delta_{4}+\Delta_{2} \Delta_{3}-\Delta_{5}<0$. When the absolute value of $\Delta_{1} \Delta_{4}+\Delta_{2} \Delta_{3}-\Delta_{5}<0$ is large, it is possible that the sign of $f(\phi)=\left(\Delta_{1} \Delta_{3}\right) \phi^{2}+\left(\Delta_{1} \Delta_{4}+\Delta_{2} \Delta_{3}-\Delta_{5}\right) \phi+\Delta_{2} \Delta_{4}$ alternates. The quadratic function $f(\phi)$ is convex downwards and its intercept is positive. If the discriminant of $f(\phi)=0$ is positive, the equation $f(\phi)=0$ has two positive real roots: for $\phi \in\left(0, \phi_{1}\right)$, we have $a_{1}>0, a_{2}>0$, $a_{3}>0$, and $a_{1} a_{2}-a_{3}>0$; for $\phi \in\left(\phi_{1}, \phi_{2}\right)$, we have $a_{1}>0, a_{2}>0, a_{3}>0$, and $a_{1} a_{2}-a_{3}<0$; and for $\phi>\phi_{2}$, we have $a_{1}>0, a_{2}>0, a_{3}>0$, and $a_{1} a_{2}-a_{3}>0$. There thus occurs the Hopf bifurcation at $\phi=\phi_{1}$ and $\phi=\phi_{2}$. Indeed, at $\phi=\phi_{1}$ and $\phi=\phi_{2}$, we have $a_{1}>0, a_{2}>0, a_{3}>0, a_{1} a_{2}-a_{3}=0$, and $\partial\left(a_{1} a_{2}-a_{3}\right) /\left.\partial \phi\right|_{\phi=\phi_{1} \text { or } \phi_{2}} \neq 0$, which means that all the conditions for the Hopf bifurcation are satisfied. There therefore exists a continuous family of non-constant, periodic solutions of the system around $\phi=\phi_{1}$ and $\phi=\phi_{2}$.

Second part: If the absolute value of $\partial T B / \partial \varepsilon<0$ is large, we have $\Delta_{5}<0$ and $\Delta_{1} \Delta_{4}+\Delta_{2} \Delta_{3}-\Delta_{5}>0$. We then have $a_{1}>0, a_{2}>0, a_{3}<0$, and $a_{1} a_{2}-a_{3}>0$, which means that one condition is not satisfied. The steady state equilibrium is therefore unstable.

\section{Appendix B: Numerical simulations}

Using numerical simulations, we show that the Hopf bifurcation actually occurs. For this purpose, we have to specify functional forms.

Investment function: $g_{d}=\gamma_{0} u^{\gamma_{1}} \pi^{\gamma_{2}}, \quad \gamma_{0}>0,0<\gamma_{1}<1, \gamma_{2}>0$.

Here, following Blecker (2002) and Sasaki (2010), we use the Cobb-Douglas investment function. Roughly speaking, the parametric restriction $0<\gamma_{2}<1$ corresponds to the domestically wage-led demand regime while $\gamma_{2}>1$ corresponds to the domestically profit-led demand regime.

Firms' target profit share: $\pi_{f}=\alpha_{0}+\alpha_{1} \varepsilon, \quad 0<\alpha_{0}<1, \alpha_{1}>0$,

Workers' target profit share: $\pi_{w}=\beta_{0}-\beta_{1} u-\beta_{2} \varepsilon, \quad 0<\beta_{0}<1, \beta_{1}>0, \beta_{2}>0$,

Labor productivity growth: $g_{a}=\eta u, \quad \eta>0$, 
Expenditure coefficient: $\alpha(\varepsilon)=B_{0} \varepsilon^{\rho-1}, \quad B_{0}>0,0<\rho<+\infty \quad \rho$, the elasticity of

substitution,

Export demand function: $\operatorname{ex}(\varepsilon)=A_{0} \varepsilon^{\psi}, \quad A_{0}>0,0<\psi<+\infty \quad \psi$, the price elasticity of

export demand.

In what follows, we present a numerical example that corresponds to the case where $\Omega<0$, the economy is in the domestically profit-led demand regime, and $\partial T B / \partial \varepsilon>0$ is large. First, we set the parameters as follows:

$s=0.7, \quad \gamma_{0}=0.2, \quad \gamma_{1}=0.2, \quad \gamma_{2}=1.7, \quad \alpha_{0}=0.3, \quad \alpha_{2}=0.01, \quad \beta_{0}=0.3, \quad \beta_{1}=0.2 ，$ $\beta_{2}=0.01, A_{0}=0.4, \psi=1500, \theta_{f}=0.3, \theta_{w}=0.7, \eta=0.01, \lambda=1, \bar{\varepsilon}=1, \quad p^{f}=0.01$, $B_{0}=0.3, \rho=150$.

In this numerical example, the open economy version of the Keynesian stability condition holds, workers are more responsive than firms, the two endogenously determined target profit shares are more than zero and less than unity, the inequality $\pi_{f}>\pi_{w}$ holds, and the endogenously determined expenditure share is $0<\alpha\left(\varepsilon^{*}\right)<1$.

We set initial conditions to $u(0)=0.15, m(0)=0.25$, and $\varepsilon(0)=0.98$. As figure B1 shows, there exist two Hopf bifurcation points.

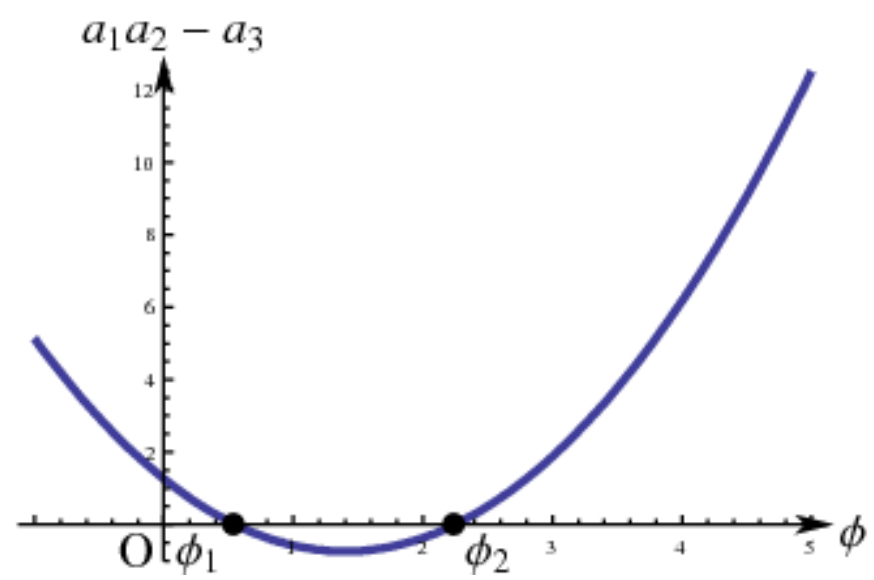

Figure B1: Existence of two Hopf bifurcation points

Using $\phi=1$ as the speed of adjustment of the goods market, we obtain the following 
figures with regard to the time series of the endogenous variables (figures B2-B5).

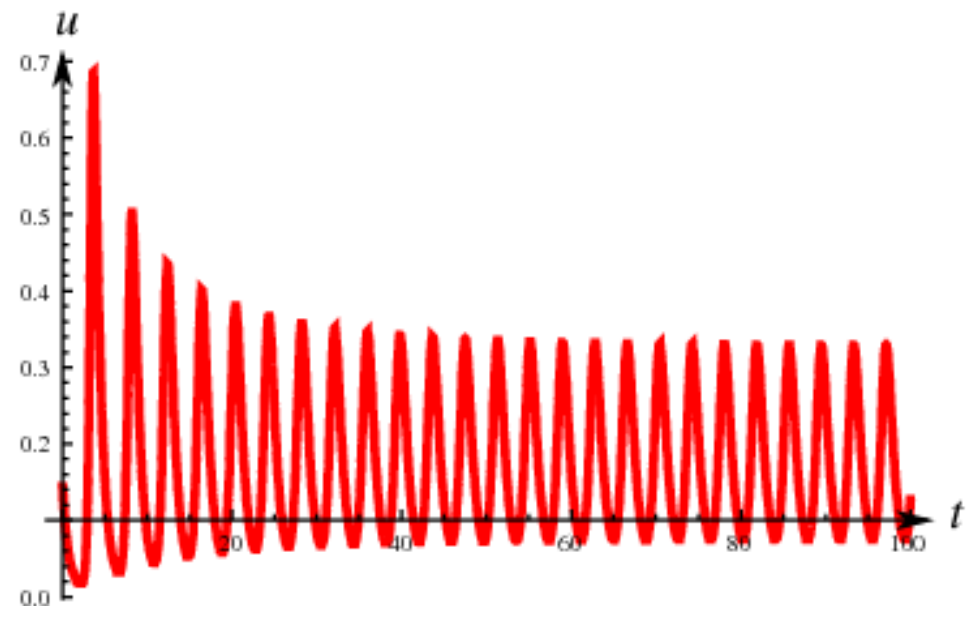

Figure B2: Dynamics of the capacity utilization

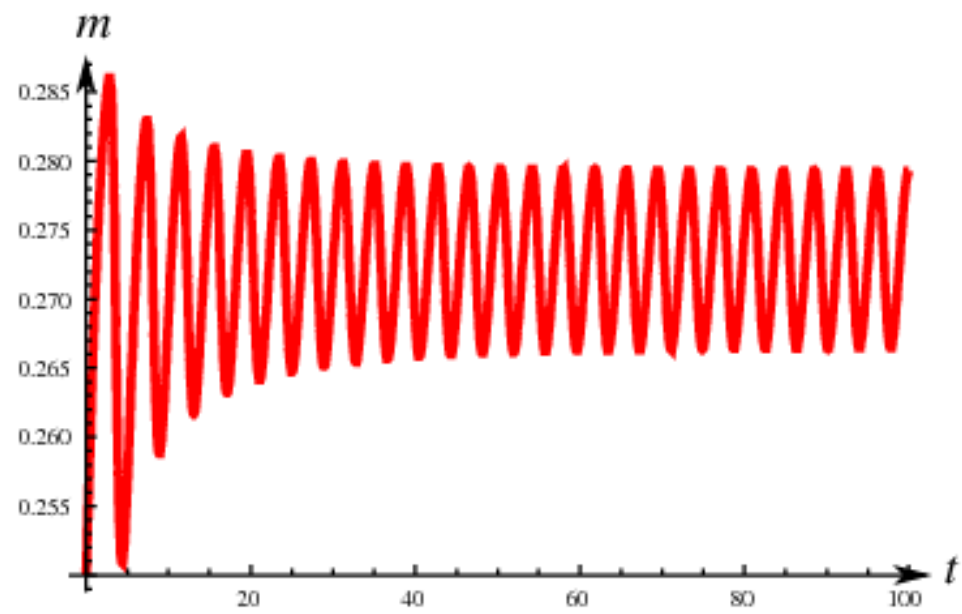

Figure B3: Dynamics of the profit share

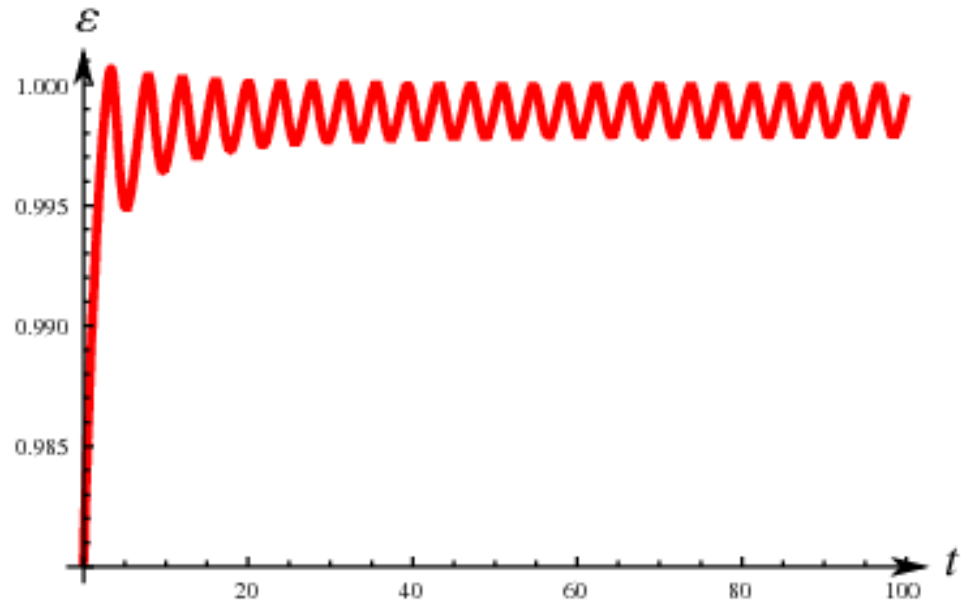

Figure B4: Dynamics of the real exchange rate 


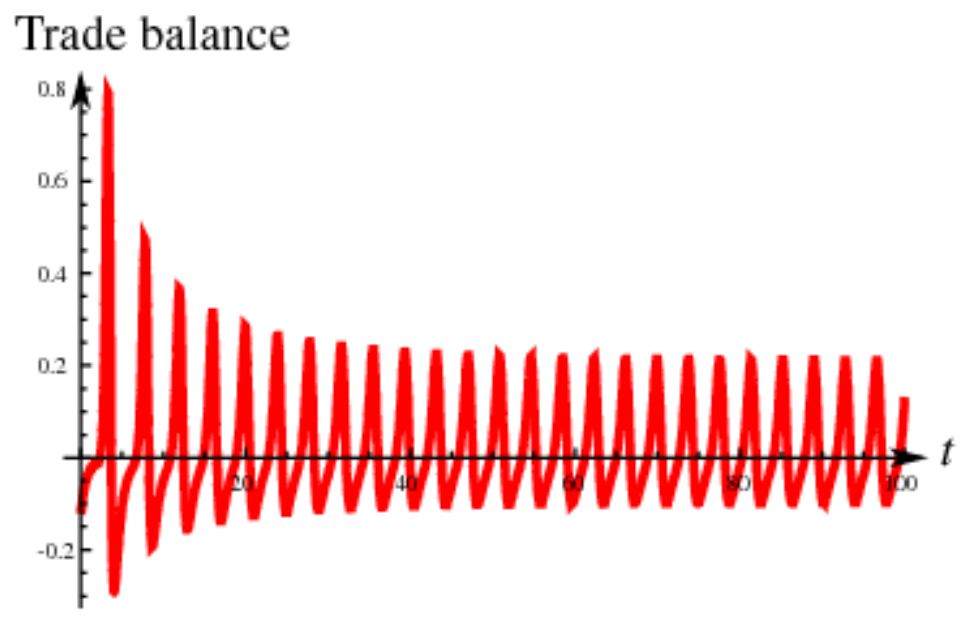

Figure B5: Dynamics of the trade balance

\section{Appendix C: Closed economy model}

We briefly explain the closed economy model, which is a model that removes import and export demand as well as the effect of the real exchange rate from the open economy model. In this case, the dynamics of the rate of capacity utilization and the profit share are as follows:

$$
\begin{gathered}
\dot{u}=\phi\left\{g_{d}(u, \pi)-s u \pi\right\}, \\
\dot{\pi}=(1-\pi)\left\{\theta_{f}\left[\pi_{f}(\mu)-\pi\right]-\theta_{w}\left[\pi-\pi_{w}(u ; \omega)\right]+g_{a}(u)\right\} .
\end{gathered}
$$

The steady state equilibrium is given by $\dot{u}=\dot{\pi}=0$.

The elements of the Jacobian matrix are given by

$$
\begin{gathered}
J_{11}=\phi\left(g_{d u}-s \pi\right), \\
J_{12}=\phi\left(g_{d \pi}-s u\right), \\
J_{21}=(1-\pi)\left[\theta_{w} \pi_{w}^{\prime}(u ; \omega)+g_{a}^{\prime}(u)\right]=(1-\pi) \Omega, \\
J_{22}=-\left(\theta_{f}+\theta_{w}\right)(1-\pi)<0 .
\end{gathered}
$$

All the elements are evaluated at the steady sate equilibrium values.

Similar to the open economy model, we use the following three assumptions.

Assumption 1'. $g_{d u}-s \pi<0$.

Assumption 2'. $g_{d \pi}-s u<0$ and $\Omega>0$.

Assumption 3'. $g_{d \pi}-s u>0$ and $\Omega<0$. 
From assumption 1', we have $\operatorname{tr} \mathbf{J}<0$. The determinant is given by

$$
\operatorname{det} J=\phi(1-\pi)\left[\left(\theta_{f}+\theta_{w}\right)\left(s \pi-g_{d u}\right)-\left(g_{d \pi}-s u\right) \Omega\right] .
$$

Under assumption 2', we have $\operatorname{det} \mathbf{J}>0$. In addition, under assumption 3', we have $\operatorname{det} \mathbf{J}>0$. If assumptions 1' and 2' hold simultaneously or if assumptions 1' and 3' hold simultaneously, we have both $\operatorname{tr} \mathbf{J}<0$ and $\operatorname{det} \mathbf{J}>0$, which thus satisfies the necessary and sufficient conditions for the local stability of the equilibrium.

We investigate the effects of exogenous increases in $\mu$ (i.e., the bargaining power of firms) and $\omega$ (i.e., the bargaining power of workers) on the equilibrium rate of capacity utilization. Totally differentiating the equilibrium conditions, we obtain

$$
\begin{aligned}
& \frac{d u^{*}}{d \mu}=\frac{\phi(1-\pi) \theta_{f} \pi_{f \mu}\left(g_{d \pi}-s u\right)}{\operatorname{det} \mathbf{J}} . \\
& \frac{d u^{*}}{d \omega}=\frac{\phi(1-\pi) \theta_{w} \pi_{w \omega}\left(g_{d \pi}-s u\right)}{\operatorname{det} \mathbf{J}} .
\end{aligned}
$$

We have that $\operatorname{det} \mathbf{J}>0$ from the stability condition. Then, if $g_{d \pi}-s u>0$, we have $d u^{*} / d \mu>0$ and $d u^{*} / d \omega<0$, and if $g_{d \pi}-s u<0$, we have $d u^{*} / d \mu<0$ and $d u^{*} / d \omega>0$. Consequently, if the economy is in the profit-led demand regime, an increase in the bargaining power of firms and an increase in the bargaining power of workers increases and decreases the rate of capacity utilization, respectively. Whereas if the economy is in the wage-led demand regime, an increase in the bargaining power of firms and an increase in the bargaining power of workers decreases and increases the rate of capacity utilization, respectively. 


\section{References}

Arnim, R. (2011): 'Wage policy in an open-economy Kalecki-Kaldor model: a simulation study', Metroeconomica, 62 (2), pp. 235-264.

Barbosa-Filho, N. H., Taylor, L. (2006): 'Distributive and demand cycles in the US economy — a structuralist Goodwin model', Metroeconomica, 57 (3), pp. 389-411.

Bhaduri, A. (2006): 'Endogenous economic growth: a new approach', Cambridge Journal of Economics, 30 (1), pp. 69-83.

Blecker, R. A. (1989): 'International competition, income distribution and economic growth', Cambridge Journal of Economics, 13 (3), pp. 395-412.

Blecker, R. A. (1996): 'The new economic integration: structuralist models of north-south trade and investment liberalization', Structural Change and Economic Dynamics, 7 (3), pp. 321-345.

Blecker, R. A. (1998): 'International competition, relative wages and the balance-of-payments constraint', Journal of Post Keynesian Economics, 20 (4), pp. 495-526.

Blecker, R. A. (2002): 'Distribution, demand and growth in neo-Kaleckian macro-models', in Setterfield, M. (ed.): The Economics of Demand-Led Growth, Challenging the Supply-Side Vision of the Long Run, Edward Elgar, Cheltenham, pp. 129-152.

Blecker, R. A. (2011): 'Open economy models of distribution and growth', in Hein, E., Stockhammer, E. (eds.): A Modern Guide to Keynesian Macroeconomics and Economic Policies, Edward Elgar, Cheltenham, pp. 215-239.

Blecker, R. A., Seguino, S. (2002): 'Macroeconomic effects of reducing gender wage inequality in an export-oriented, semi-industrialized economy', Review of Development Economics, 6 (1), pp. 103-119.

Cassetti, M. (2002): 'Conflict, inflation, distribution and terms of trade in the Kaleckian model', in Setterfield, M. (ed.): The Economics of Demand-Led Growth, Challenging the Supply-Side Vision of the Long Run, Edward Elgar, Cheltenham, pp. 189-211.

Cassetti, M. (2003): 'Bargaining power, effective demand and technical progress: a Kaleckian model of growth', Cambridge Journal of Economics, 27 (3), pp. 449-464.

Cassetti, M. (2012): 'Macroeconomic outcomes of changing social bargains: the feasibility of a wage-led demand open economy reconsidered', Metroeconomica, 63 (1), pp. 64-91.

Cordero, J. A. (2002): 'A model of growth and conflict inflation for a small open economy', Metroeconomica, 53 (3), pp. 261-289. 
Dutt, A. K. (1987): 'Alternative closures again: a comment on growth, distribution and inflation', Cambridge Journal of Economics, 11 (1), pp. 75-82.

Dutt, A. K. (2006): 'Aggregate demand aggregate supply and economic growth', International Review of Applied Economics, 20 (3), pp. 319-336.

Flaschel, P., Skott, P. (2006): 'Steindlian models of growth and stagnation', Metroeconomica, 57 (3), pp. 303-338.

Hein, E., Vogel, E. (2008): 'Distribution and growth reconsidered: empirical results for six OECD countries', Cambridge Journal of Economics, 32 (3), pp. 479-511.

Lavoie, M. (1992): Foundations of Post-Keynesian Economic Analysis, Edward Elgar, Cheltenham.

La Marca, M. (2010): 'Real exchange rate, distribution and macro fluctuations in export-oriented economies', Metroeconomica, 61 (1), pp. 124-151

Marglin, S., Bhaduri, A. (1990): 'Profit squeeze and Keynesian theory', in Marglin, S., Schor, J. (eds.): The Golden Age of Capitalism: Reinterpreting the Postwar Experience, Clarendon Press, Oxford, pp. 153-186.

Missaglia, M. (2007): 'Demand policies for long-run growth: being Keynesian both in the short and in the long run', Metroeconomica, 58 (1), pp. 74-94.

Naastepad, C. W. M., Storm, S. (2007): 'OECD demand regimes (1960-2000)', Journal of Post Keynesian Economics, 29 (2), pp. 211-246.

Naastepad, C. W. M., Storm, S. (2010): 'Feasible egalitarianism: demand-led growth, labour and technology', in Setterfield, M. (ed.): Handbook of Alternative Theories of Economic Growth, Edward Elgar, Cheltenham.

Rowthorn, R. E. (1977): 'Conflict, inflation and money', Cambridge Journal of Economics, 1 (3), pp. 215-239.

Rowthorn, R. E. (1981): 'Demand, real wages and economic growth', Thames Papers in Political Economy, Autumn, pp. 1-39.

Sasaki, H. (2010): 'Endogenous technological change, income distribution, and unemployment with inter-class conflict', Structural Change and Economic Dynamics, 21 (2), pp. 123-134.

Sasaki, H. (2011): 'Conflict, growth, distribution, and employment: a long-run Kaleckian model', International Review of Applied Economics, 25 (5), pp. 539-557.

Sasaki, H. (2013): 'Cyclical growth in a Goodwin-Kalecki-Marx model', Journal of 
Economics, 108(2), pp.145-171.

Stockhammer, E., Hein, E., Grafl, L. (2011): 'Globalization and the effects of changes in functional income distribution on aggregate demand in Germany', International Review of Applied Economics, 25 (1), pp. 1-23.

Stockhammer, E., Onaran, Ö. (2004): 'Accumulation, distribution and employment: a structural VAR approach to a Kaleckian macro model', Structural Change and Economic Dynamics, 15 (4), pp. 421-447.

Stockhammer, E., Onaran, Ö., Ederer, S. (2009): 'Functional income distribution and aggregate demand in the Euro area', Cambridge Journal of Economics, 33 (1), pp. $139-159$.

Storm, S., Naastepad, C. W. M. (2007): 'It is high time to ditch the NAIRU', Journal of Post Keynesian Economics, 29 (4), pp. 531-554.

Tavani, D., Flaschel, P., Taylor, L. (2011): 'Estimated non-linearities and multiple equilibria in a model of distributive-demand cycles', International Review of Applied Economics, 25 (5), pp. 519-538.

Thirlwall, A. P. (1979): 'The balance of payments constraint as an explanation of international growth rate differences', Banca Nazionale del Lavoro Quarterly Review, 32 (1), pp. $45-53$. 
Figure and Tables

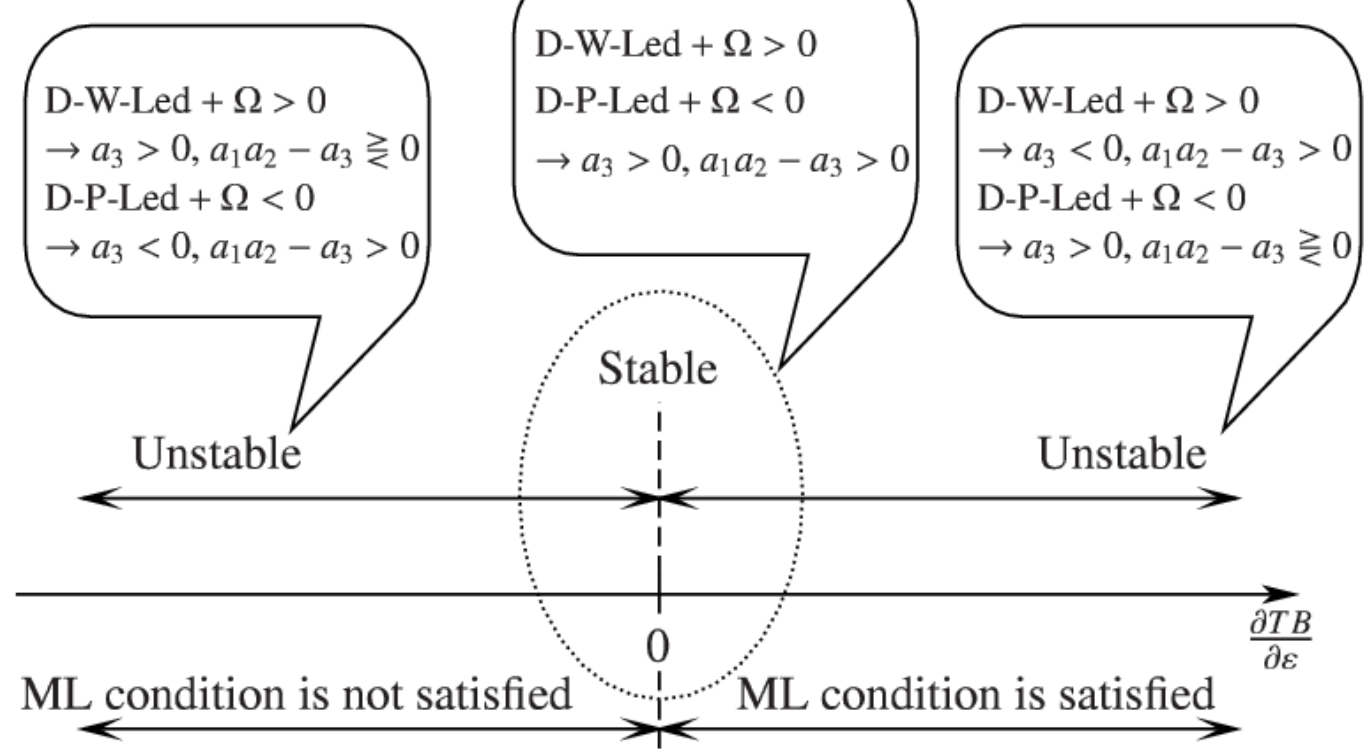

D-W-Led: Domestically Wage-Led; D-P-Led: Domestically Profit-Led

Figure 1: Diagram of stability analysis

Table 1: Results for comparative static analysis under the domestically wage-led demand regime and $\Omega>0$

\begin{tabular}{c|ccc}
\hline & $u^{*}$ & $\pi^{*}$ & $\varepsilon^{*}$ \\
\hline \hline$s$ & - & - & - \\
$\mu$ & + or - & + or - & + or - \\
$\omega$ & + or - & - & - \\
$\bar{\varepsilon}$ & + or - & + or - & + \\
\hline
\end{tabular}

Table 2: Results for comparative static analysis under the domestically profit-led demand regime and $\Omega<0$

\begin{tabular}{c|ccc}
\hline & $u^{*}$ & $\pi^{*}$ & $\varepsilon^{*}$ \\
\hline \hline$s$ & - & + & + \\
$\mu$ & + or - & + or - & + or - \\
$\omega$ & - & - & - \\
$\bar{\varepsilon}$ & + or - & + or - & + \\
\hline
\end{tabular}

